\title{
Research on color planning of campus buildings in Shenyang Jianzhu University
}

\author{
Mei Lyu ${ }^{1, \text { a }}$, Jiahao Liu' ${ }^{2, b}$, HengYu Zhang ${ }^{3, \text { c }}$, Dong Sun ${ }^{4, \mathrm{~d}}$ \\ ${ }^{1}$ School of design and art, Shenyang Jianzhu University, China \\ ${ }^{2}$ School of design and art, Shenyang Jianzhu University, China \\ ${ }^{3}$ School of design and art, Shenyang Jianzhu University, China \\ ${ }^{4}$ School of Architecture and Urban Planning, Shenyang Jianzhu University, China
}

\begin{abstract}
This paper is based on the perspective of regional architectural color planning and selecting campus buildings in cold regions as an example, taking architectural color as the research object, making a multiviewpoint research on the use of color and its influencing factors. This article conducts actual investigation on the color of exterior facades of buildings in different areas of Shenyang Jianzhu University Campus, systematic evaluation and suggestion on architectural color of Shenyang Jianzhu University on the basis of Munsell color solid system.
\end{abstract}

\section{Introduction}

When the reflection of light is mapped to the human eyes, color is produced. It's closely related to human physiological structure, forming color perception and perception effect and then further stimulate human potential physiological and psychological responses. People live in space, which is full of architectural colors. It affects human visual nerve, and then reflects the psychological demands of living environment.

Architectural color can be divided into architectural appearance color and interior color. In this study, the object is only to analyze and interpret the architectural appearance color. Its composition includes the color of the building facade, the color of the building roof and the relationship between the color of the building monomer and the color of the building complex.

\section{The function of architectural color and the importance of campus architectural color planning}

The buildings and its external environment is related to the architectural color of planning and design. Proper use of architectural color is one of the important elements in evaluating the visual effect of buildings. If the architectural color matching effect is excellent, audiences can accurately perceive the characteristics of buildings and deeply understand the regional individuality of the surrounding environment of buildings. It determines the cultural personality of the city and comprehensive reflection of regional cultural background and functional attributes, besides, its creating the impression of city and regional culture.

Architectural colors in the construction of Chinese university campuses can highlight their historical origins, cultural connotations and regional characteristics, and show the advantages of teaching, disciplines and humanistic environment of the school. On the other hand, as far as students are concerned, college campus is a special environment for life in the future. The color of campus architecture makes the visual elements they see every day, which exerts a subtle influence on students' visual perception of the cultural and environmental characteristics of colleges and universities. The distinctive geographical and climatic characteristics of the four seasons in the cold region make the campus buildings in the cold region have special color feelings and characteristics. Based on this point, the author started from the perspective of architectural color planning and design of modern urbanization and directionally choose the cold campus-the facade color of the campus of Shenyan Jianzhu University as the object of study. In the process of discovering the problem, and then put forward the way of color planning and design of campus buildings in cold regions.

\section{The present state of color planning on campus buildings in Shenyang Jianzhu University}

Shenyang Jianzhu University was founded in 1977, the

alynmei@sjzu.edu.cn, b402948501@qq.com, ${ }^{\mathrm{c}} 1240536638 @ q q . c o m,{ }^{\mathrm{d}}$ sundong@sjzu.edu.cn 
original campus is located in Wenyi Road, Shenhe District, Shenyang City. And there's another east campus is located in Tiantan Street, Culture Road, Dongling District, Shenyang City. The main colors of the buildings in the former West Campus and the East Campus are mainly yellow, gray, white and brown. The old school campus have been demolished. In 2003, new campus built and put into use in Hunnan, Shenyang. It is located at No.25 Hunnan Middle Road, Hunnan District. The main campus covers an area of $1500 \mathrm{mu}$ with a building area of 500,000 square meters. The new campus includes teaching area, living area, office area, campus landscape area (paddy field, historical buildings in Shenyang), gymnasium, library, etc. The teaching area is a grid-like courtyard combination with oriental cultural connotations, which is connected with the 756-meter-long first Asian cultural corridor.

In order to accurately study the application of architectural color in the campus of Shenyang Jianzhu University, the author made a field investigation of the whole campus and we choose sunny, cloudy and cloudy weather in the morning (6:00-7:00), afternoon (2:00-3:00), evening (4:00-5:00), and select different seasons (spring, summer, autumn and winter) for research and evidence collection in order to ensure the uniformity of sample collection. The collected data are scientifically summarized and sorted out according to Munsell's color solid system. And then, according to the size of the color area, the status quo of the new and old campus building color is analyzed according to the different attributes of color (hue, lightness and purity) by the classification means of main color, auxiliary color and decorative color.

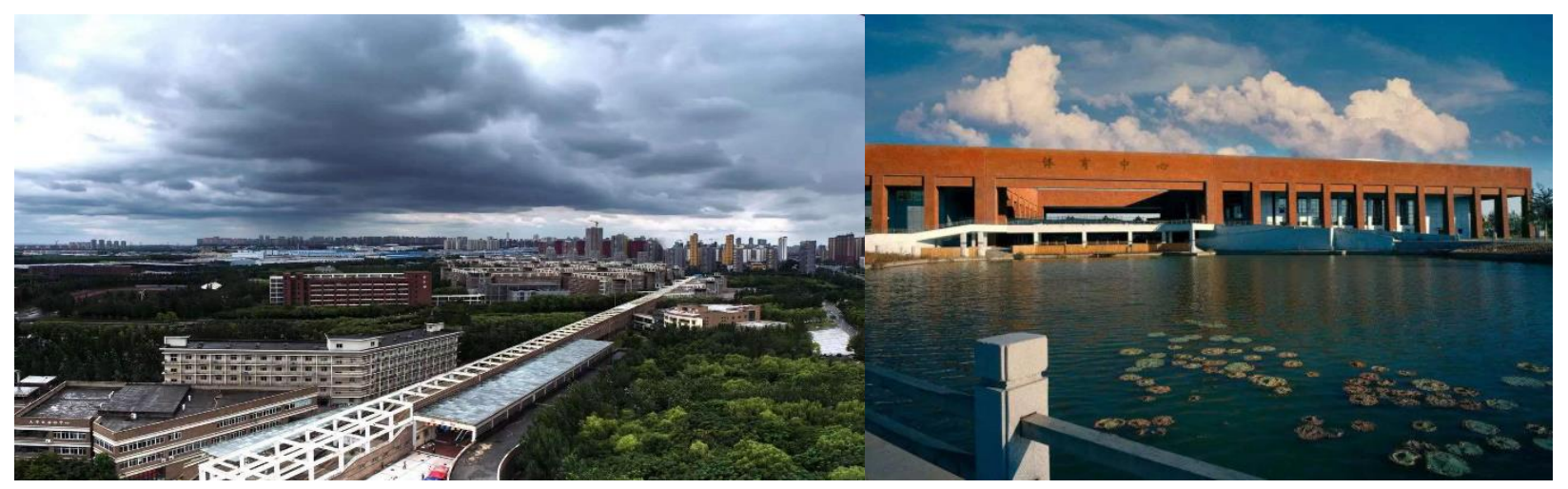

Table1 Shenyang Jianzhu University

\subsection{Analysis of architectural color}

\section{1) Teaching area}

The teaching area of Shenyang Jianzhu University is the main building of the whole campus, which is including teaching buildings, corridors, office areas, as a whole, each area is closely connected and grid-shaped, with several courtyards in the middle. Investigation shows that the main color of the teaching area is yellow-brown (YB) color system and some individual areas are using a combination of yellow-red-brown (YRB) colors. Architecture-subject color luminosity is concentrated in the range of 5-10, of which 6-7 (mid-luminosity) is the most which is about $90 \%$. The auxiliary color is mainly white (W). The decorative colors of the buildings in this area are mostly used in the doors and window frames of the buildings, as a result of there are many courtyards in the area, it is closely combined with the environmental color, and the color change is obviously affected by the season. The color purity of the main body of the building ranges from 3 to 5 , of which 4 to 5 are the most concentrated, accounting for about $80 \%$.

\section{2) Living area}

The teaching area of Shenyang Jianzhu University is the main building of the whole campus, which is including teaching buildings, corridors, office areas, as a whole, each area is closely connected and grid-shaped, with several courtyards in the middle. Investigation shows that the main color of the teaching area is yellow-brown (YB) color system and some individual areas are using a combination of yellow-red-brown (YRB) colors. Architecture-subject color luminosity is concentrated in the range of 5-10, of which 6-7 (mid-luminosity) is the most which is about $90 \%$. The auxiliary color is mainly white (W). The decorative colors of the buildings in this area are mostly used in the doors and window frames of the buildings, as a result of there are many courtyards in the area, it is closely combined with the environmental color, and the color change is obviously affected by the season. The color purity of the main body of the building ranges from 3 to 5 , of which 4 to 5 are the most concentrated, accounting for about $80 \%$.

\section{3) Library, gymnasium}

The gymnasium, library and teaching area of Shenyang Jianzhu University are relatively independent. The color of the main building is red (R), with an area of $80 \%$. Decorative colors are mostly used in the doors, window frames, exterior walls of buildings, but the color consistency is relatively high, mostly gray brown (GB) combination. The color purity of the main body of the building ranges from 3 to 5 , of which 4 to 5 are the most concentrated, accounting for about $90 \%$.

4) Historic landscape architecture

Shenyang Jianzhu University has a large number of historic buildings in the courtyard area, including the school hospital and Bawang College. The overall color of the building is gray $(\mathrm{G})$, with an area of $95 \%$. Decorative colors are mostly used in the doors, window frames, 
exterior walls of buildings, and mostly in the combination of red and green (RG). The color purity of the main body of the building ranges from 1 to 4 , of which 2 to 3 are the most concentrated, accounting for about $90 \%$.

5) Modern architecture

It mainly refers to the BOX assembled box building built in the courtyard and the China-German energy- saving center. There is a great difference in the use of colors between them. BOX assembled box building is mainly composed of red, yellow and blue (RYB) with high brightness and purity and the gray system is the dominant system in the construction center of China-German energy-saving center, accounting for $98 \%$.

Table2 The color of Shenyang Jianzhu University buildings

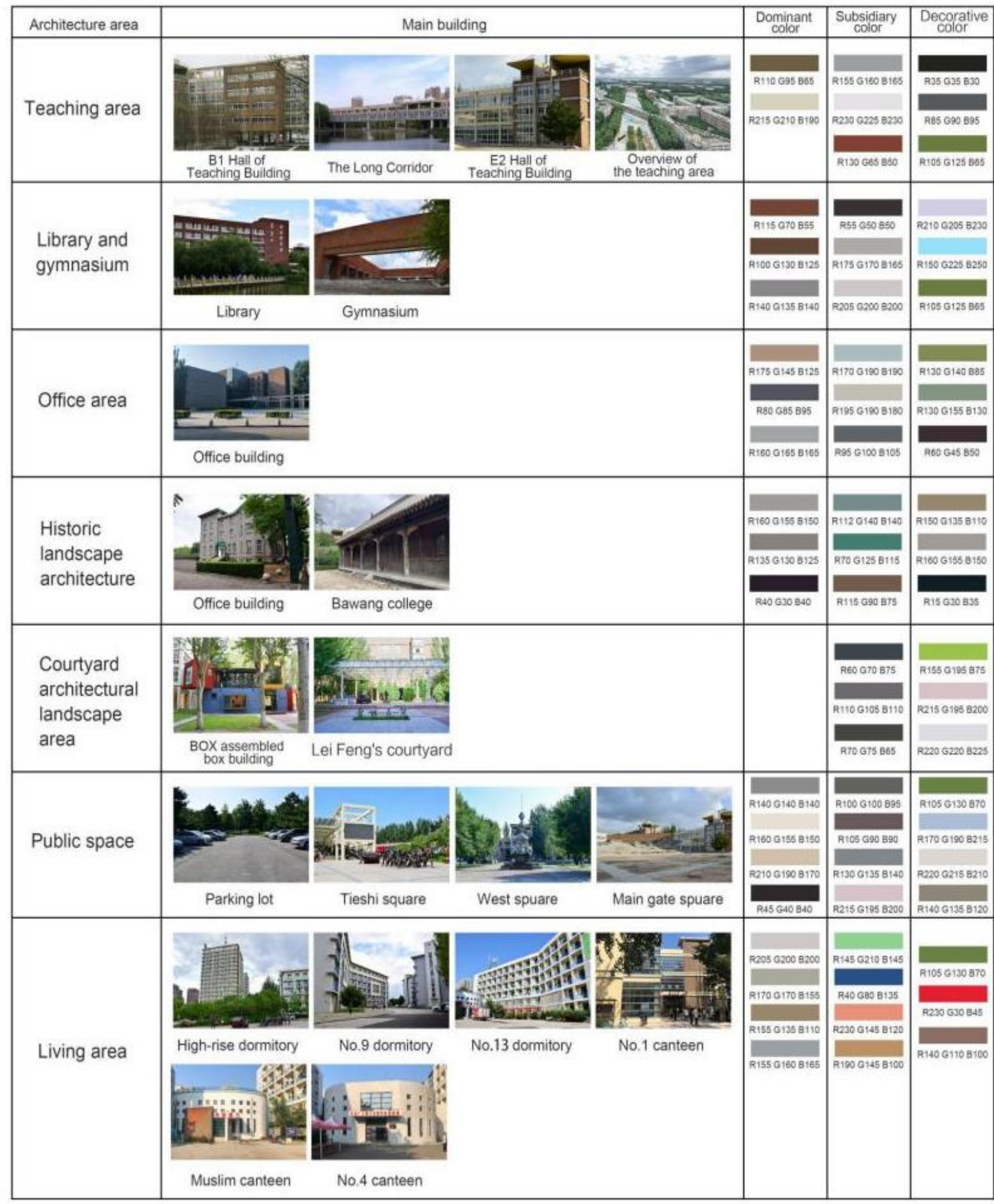




\section{Existing problems and optimizing measures}

\subsection{Problems}

In the process of investigating and analyzing the overall architectural color of Shenyang Jianzhu University, the following problems are found. The color of the main building is single and unchanged, and the space sense of vision needs to be strengthened. The relative harmony and consistency of architectural colors in teaching and living areas is the independence of colors in individual areas. There is no complete contrast and correlation between them, and the system needs to be strengthened. There is no correspondence between environmental landscape and architectural color. They are independent. Landscape sketches and the color of space markers are arbitrary in design and weak in coordination with space. The relationship between the color of individual entrance space and the corresponding color of the building street space around the city is weak. The color relationship around the central water system should be more integrated. The color relations around each square in the campus, such as entrance square, Longtan square and Tieshi square, are isolated and inconsistent. The main courtyards on campus, such as Lei Feng's courtyard and dormitory courtyard, are mostly of the same color and have low recognition. BOX assembled box building are brightly colored, but they are slightly colourful collocates with courtyard architectures. The color of the parking lot is rather monotonous. Without space landscape design and color design, it is impossible to form a system with the surrounding building color in spring, summer and autumn because of the tree shelter.

Table 3 Four seasons colors of Shenyang Jianzhu University buildings
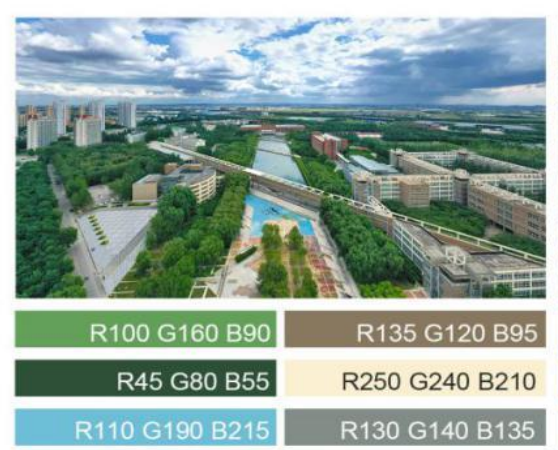

\subsection{Optimized Ways}

The overall visual effect of architectural color shows the style and characteristics of the area. People who are active in the region often feel the architectural color in close proximity and are more likely to have a connection with psychology. In the process of campus color optimization, when the detail color matches with the macro architectural color, it should be planned from the perspective of color psychology.

1) We need to enhance the continuity and systematicness of the colors in each region. From the perspective of color recognition, coordinate the relationship between the surrounding environment and architecture. Further optimize the color of campus landscape, make rational use of regional landscape, highlight the campus culture and realize the continuity of color.

2) In the process of color planning, colleges have the problem of homogeneity. As a cold region college, we should further strengthen the unique regional characteristics of the north through color design.

3) While reflecting the campus culture through color, we actively put forward the color garbage, find the characteristics suitable for our school, retain the color characteristics of the combination of regional and cultural context.

In fact, colleges and universities are the areas where people are concentrated. Its nature and characteristics also determine the use and collocation of architectural colors in colleges and universities. Architectural color design in art colleges can be different and bold, seeking novelty. While in normal colleges and universities, architectural color design should be simple, calm and generous. The research on campus architectural color in colleges and universities can reflect its current situation and problems more intuitively, which plays an important role in shaping a high-quality campus cultural atmosphere, establishing a good campus color landscape and continuing the urban regional characteristics.

\section{Acknowledgements}

This work was funded by Project of Liaoning Provincial Department of Education Foundation. Research on design theory and methods of microclimate adaptability of the landscape in open space on campus. (LJZ2016010) and ShenYang JianZhu University General Foundation. "Two Mausoleum, One Palace" in ShenYang: Study on the acquisition and digitization of spatial color elements. (2017011) 


\section{References}

1. Bridget. Architectural facade and color [M]. Liaoning Science and Technology Press, 2010.

2. Yuan Dongyang. Research on color expression of building facade based on regional characteristics [D]. Dalian University of Technology, 2016.

3. Li Congxia. A comparative study of architectural colours between old and new campuses in Universities [D]. Shandong Agricultural University, 2015.

4. G. Barone,M. Fugazzotto,P. Mazzoleni,S. Raneri,A. Russo. Color and painting techniques in Etruscan architectural slabs[J]. Dyes and Pigments,2019,171.

5. Energy - Solar Energy; Reports from Technical University Provide New Insights into Solar Energy (Color rendering performance of smart glazings for building applications)[J]. Energy Weekly News,2019.

6. JIAN-MIN DONG,LI-NING LI. Construction Feature of Intrinsic Color Vector Span Space on Appearance of Tibetan Traditional Architecture from Digital Images[P]. DEStech Transactions on Computer Science and Engineering,2018. 